\title{
Nosocomial pneumonia during mechanical ventilation: problems with diagnostic criteria
}

Nosocomial pneumonia is thought to be the leading cause of nosocomial infections in the intensive care unit (ICU), and is associated with the highest case fatality ratio. ${ }^{1}$ Large variations have, however, been reported in the attack rate of pneumonia, ranging from $9 \%$ to more than $60 \%$ of patients at risk. Likewise, the morbidity and mortality are uncertain, ranging from 0 to $50 \%$ of affected patients. ${ }^{12}$ Although the case mix of patients and setting of studies may explain some of these variations, most can be accounted for by the differing criteria used to diagnose pneumonia between studies. The diagnosis of nosocomial (ventilator acquired) pneumonia remains a challenge and the source of considerable debate. ${ }^{34}$ This uncertainty has important consequences for both clinical research and practice. For example, whether mortality is the appropriate end point to test the efficacy of preventive measures of ventilator associated pneumonia such as selective decontamination ${ }^{5}$ is unknown, and depends on the expected impact of pneumonia on the outcome. Similarly, whether reliable and useful information can be gained from studies of risk factors of pneumonia is open to question if half of the population studied does not actually have the disease but has only bronchitis or bacterial colonisation. In addition, we may be unnecessarily administering antibiotics to patients suspected of ventilator acquired pneumonia, thus encouraging the development of antibiotic resistance in the hospital environment. Alternatively, we may be delaying treatment by using over restrictive diagnostic criteria, thus potentially increasing the morbidity of the infection. Obviously, some consensus has to be reached on the appropriate means by which to recognise and diagnose acquired pneumonia. ${ }^{6}$

While traditional clinical criteria (presence of fever, purulent sputum and leucocytosis, together with the appearance of new radiographic infiltrates) have an acceptable accuracy for diagnosing nosocomial pneumonia in the nonintubated patient, these criteria have been repeatedly shown to be both insensitive and non-specific in mechanically ventilated patients. ${ }^{78}$ This is particularly true in patients with pre-existing pulmonary abnormalities and in those with diffuse lung injury. ${ }^{79-11}$ Meduri et al, for example, found that a thorough evaluation of fever in 50 mechanically ventilated patients suspected of pneumonia resulted in only $42 \%$ of them being diagnosed as actually having pneumonia, with other causes of fever and/or pulmonary densities in the others. ${ }^{12}$ Clinical and radiographic criteria must therefore be complemented by microbiological criteria. Having said this, it does not solve the problem, as it leads to even more confusion than the issue of clinical criteria - namely, which sampling technique should be used for obtaining microbiological information, and how reliable are these techniques in mechanically ventilated patients? Unfortunately, much of the recent literature has provided more confusion than help in clarifying these issues.

Because of the widespread colonisation of the airways, including the trachea and central airways in intubated patients, ${ }^{13}$ two steps have been taken in devising methods for sampling lower respiratory secretions: (1) sampling via protected devices to minimise contamination when the device is passed through the endotracheal tube and upper airways; and (2) the use of quantitative cultures to help distinguish between infecting and contaminating or colonising organisms. A number of techniques with various degrees of sophistication along these lines have been proposed in the past 10 years, including the protected (doublesheathed) specimen brush, the protected (single-sheathed) catheter, protected mini-bronchoalveolar lavage, and standard (protected or not) bronchoalveolar lavage; all except standard bronchoalveolar lavage have been performed "blindly" or via fibreoptic bronchoscopy. ${ }^{814-16}$ Whatever the technique used, quantitative cultures appear to be mandatory to ensure the discriminatory power of the sample. ${ }^{11}$ Some recent studies, for example, have compared the diagnostic value of endotracheal aspirates and new sampling techniques. ${ }^{178}$ They all confirm the high sensitivity of an endotracheal aspirate, but also its unacceptably low specificity unless quantitative cultures are performed; however, a very high diagnostic threshold $\left(\geqslant 10^{6} \mathrm{cfu} / \mathrm{ml}\right.$ ) should then be selected which results in a loss of diagnostic sensitivity. It is illusory to expect any single diagnostic test to have $100 \%$ sensitivity and specificity, and the choice of a particular technique (or even of a combination of techniques) may depend on whether the emphasis is put on sensitivity or on specificity.

How much more accurate than traditional sampling techniques such as the simple endotracheal aspirate are these new techniques, and how do they compare with each other? There are two ways of approaching this problem: one is to compare the yield of one (experimental) technique with another, taken as the standard. Another more scientifically valid approach - because there is no widely accepted reference sampling technique - is to evaluate the information given by one or several sampling methods while the presence or absence of pneumonia is ascertained by an independent test. Needless to say, there are many more studies corresponding to the first design than to the second because the only test that is widely accepted as definitive is histological demonstration of the pneumonia. ${ }^{6}$ There are, however, many practical problems here which limit one to general inferences, as histological examination can only be performed at an immediate necropsy where lung cultures can also be obtained. This limits the patients studied to those who have severe underlying disease and/or pneumonia, and the results may not be applicable to those with less severe or advanced forms of the disease. There are also major problems with the interpretation of both the pathological and microbiological data obtained from a necroscopic study in patients who have received mechanical ventilation for several days as they often have a history of prior lung disease which may interfere with the interpretation of the pathological findings. In addition, and more importantly, many experience some acute lung injury during the mechanical ventilation. Histological changes consistent with pneumonia found at necroscopic examination after several days of mechanical ventilation may be extremely difficult to ascribe to a current episode of active lung infection, or to a prior or partially resolved episode. A combination of histological findings with lung culture results may improve the diagnostic yield in this context. A major confounding factor for the interpretation of lung culture results is that most patients have received antibiotics during their ICU stay, and many receive treatment with antimicrobial drugs until death and pulmonary sampling which may invalidate culture results. Indeed, follow up protected specimen brush samples taken at 24 and 48 hours in patients with ad- 
equately treated pneumonia show a rapid decrease in bacterial counts. ${ }^{19}$ This may explain why patients with histological findings consistent with bronchopneumonia have been found to have a very low bacterial burden in the lung $\left(<10^{3}\right.$ in $68 \%$ of lobes with "characteristic lesions of bronchopneumonia", about half of which were culture negative). ${ }^{20}$ These data contrast with experimental pneumonia in animals and acute lung infection in humans, ${ }^{21}$ which led to the suggestion that the threshold for diagnosing bronchopneumonia by culture of lung biopsy samples should be lowered to $<10^{4} / \mathrm{g}$ tissue. ${ }^{20}$ An alternative (and more likely) explanation is that these patients may have had an episode of bronchopneumonia dating back several days before sampling which had partially resolved or was inactive at the time of sampling because of prior treatment with antibiotics, with the respiratory tract samplings taken at the time of death representing airway colonisation or tracheobronchitis - that is, false positives. Torres et $a^{p^{2}}$ also compared lung histological and culture results with those of several respiratory tract sampling techniques in 30 patients who had died after a mean of nine days of mechanical ventilation, all of whom had received prior antibiotics, including 18 patients with prior pneumonia. When compared with the histological presence of bronchopneumonia (found in necroscopic lung biopsy samples from 18 of 30 patients), both the sensitivity and specificity of all respiratory tract sampling methods tested (tracheal aspiration, protected specimen brush, and bronchoalveolar lavage) were unacceptably low $(\leqslant 50 \%)$. It is not known how many patients in this study had a clinical diagnosis of a new episode of acquired bronchopneumonia, and whether results differed in patients with or without prior lung disease. The authors concluded that lung histological and microbiological findings on immediate necroscopic biopsy samples are an inadequate "gold standard" in patients receiving antibiotics, and that the previously established thresholds for sampling techniques of respiratory secretions are unable to differentiate patients with and without pneumonia. It may be added that it seems inadequate to compare lung histological results and cultures with cultures of respiratory tract samples to assess the validity of such samples in patients on antibiotics.

A final problem with necroscopic lung cultures is the rapid proliferation of organisms immediately following death. Wilson $e t a l^{23}$ have shown that bacterial counts up to $10^{4} \mathrm{cfu} / \mathrm{g}$ of lung tissue were found in $30 \%$ of patients examined within hours of death from causes other than pneumonia and in the absence of histological findings suggestive of pneumonia.

It is quite clear from the above that the selection of patients for studies using necroscopic histological examination and lung cultures to assess the diagnostic accuracy of respiratory secretion sampling techniques must be done very carefully, and their results interpreted cautiously. In fact, it appears difficult to avoid the many pitfalls for performing a valid study in the clinical setting, and the necessary requirements are more likely to be obtained in the experimental setting. It is noteworthy that some experimental studies provide much clearer answers to the questions raised above than clinical studies performed in a similar but less well controlled setting. In this regard, the most relevant investigations have been by Johanson and colleagues $^{24} 25$ in baboons with experimental lung injury. In animals not given antibiotics they found that the sensitivity of the protected specimen brush method for diagnosing pneumonia was $70 \%$ (seven of 10 baboons with pneumonia as assessed by histological examination, lung aspirate, and blood cultures) and its specificity was $100 \%$. In a subsequent study the severity of the protected specimen brush method to detect bacteria in the lung in a concentration of $>10^{3} / \mathrm{g}$ tissue (in the absence of antibiotics) was $63 \%$ and that of bronchoalveolar lavage was $100 \% .^{22}$ These studies also confirmed the very high rate of false positive results of tracheal aspirates (40-100\%) which offsets the high sensitivity of this sampling technique.

Although the analysis of the sensitivity of sampling techniques compared with histological analysis and cultures of lung tissue may be possible only in the experimental setting, there remains the possibility of assessing the specificity of pulmonary secretion samples in patients with no evidence of pneumonia during the course of mechanical ventilation and no recent ( $<72$ hours) administration or change in antibiotics who are dying from a cause other than pneumonia, ultimately confirmed by necroscopic lung examination. Unfortunately no studies of this design are available. Rouby et al studied 29 patients (only four of whom eventually died) with no clinical evidence of pneumonia during their ICU stay who had received mechanical ventilation for a mean of 14 days $^{26} ; 14$ of the 51 minibronchoalveolar lavage samples taken were culture positive in 10 of the 29 patients but, unfortunately, no quantitative culture was performed to help distinguish contaminated samples. Torres $e t a l^{27}$ studied 27 patients with no clinical evidence of pneumonia who were ventilated for a mean of seven days. Lung biopsy samples were not obtained and most were receiving antibiotics, which may favour colonisation of the airways. All but two had microbial growth from tracheal aspirates ( $\geqslant 10^{5} \mathrm{cfu} / \mathrm{ml}$ in $48 \%$ of samples), $41 \%$ had bacterial counts of $\geqslant 10^{3} \mathrm{cfu} / \mathrm{ml}$ recovered by the protected specimen brush method, and $35 \%$ had $\geqslant 10^{4}$ $\mathrm{cfu} / \mathrm{ml}$ in bronchoalveolar lavage fluid. The very high rate of false positives from the protected specimen brush and bronchoalveolar lavage samples recorded in this study is disturbing. However, high counts of non-pathogenic oropharyngeal organisms were recovered from many of the positive samples, which suggests that there were technical problems with the techniques used.

Much of the confusion in the evaluation of diagnostic strategies in ventilator-associated pneumonia arises from studies that have used inadequate methodology to answer the problems posed. Although critically ill patients undergoing mechanical ventilation are notoriously difficult to study, some basic principles in the diagnostic evaluation of bacterial cultures should not be overlooked. Among these are careful selection of patients and strict observation of technical detail; samples should be taken before antibiotics are given or, at least, before any change in antimicrobial treatment prior to the onset of the new clinical findings suggestive of infection.

Service de Réanimation Médicale, CHRISTIAN BRUN-BUISSON Hôpital Henri Mondor,

Université Paris XII,

94010 Créteil,

France

1 George DL. Epidemiology of ventilator-associated pneumonia. Infect Control Hosp Epidemiol 1993;14:163-9.

2 Fagon JY, Chastre J, Hance AJ, Montravers P, Novara A, Gibert C. Nosocomial pneumonia in ventilated patients: a cohort study evaluating attributable mortality and hospital stay. $A m \mathcal{F}$ Med 1993;94:281-8.

3 Niederman MS, Torres A, Summer W. Invasive diagnostic testing is not needed routinely to manage suspected ventilator-associated pneumonia. Am 7 Respir Crit Care Med 1994;150:565-9.

4 Chastre J, Fagon JY. Invasive diagnostic testing should be routinely used to manage ventilated patients with suspected pneumonia. Am $\mathcal{f}$ Respir Crit Care Med 1994;150:570-4.

5 Brun-Buisson C. Selective decontamination of the digestive tract: interpreting the synthetized evidence. Chest 1994,105:978-80.

6 First International Consensus Conference on the clinical investigation of ventilator-associated pneumonia. Infect Control Hosp Epidemiol 1992;13: 633-77.

7 Andrews CP, Coalson JJ, Smith JD, Johanson WG. Diagnosis of nosocomial bacterial pneumonia in acute, diffuse lung injury. Chest 1981;80:254-8.

8 Fagon JY, Chastre J, Hance AJ, Guiguet M, Trouillet JL, Domart Y, et al. Detection of nosocomial lung infection in ventilated patients. Use of a protected specimen brush and quantitative culture techniques in 147 patients. Am Rev Respir Dis 1988;138:110-6. 
9 Wunderink RG, Woldenberg LS, Zeiss J, Day CM, Ciemons J, Lacher DA. Radiologic diagnosis of autopsy-proven ventilator-associated pneumonia. Chest 1992;101:458-63.

10 Bell RC, Coalson JJ, Smith JD, Johanson WG. Multiple organ system failure and infection in adult respiratory distress syndrome. Ann Intern Med 1983; 99:293-8.

11 Montgomery AB, Stager MA, Carrico CJ, Hudson LD. Causes of mortality in patients with the adult respiratory distress syndrome. Am Rev Respir Dis 1985;132:485-9.

12 Meduri GU, Mauldin GL, Wunderink RG, Leeper KV, Jones CB, Tolley $\mathrm{E}$, et al. Causes of fever and pulmonary densities in patients with clinical manifestations of ventilator-associated pneumonia. Chest 1994;106:22135 .

13 Higuchi JH, Johanson WG. Colonization and bronchopulmonary infection. Clin Chest Med 1982;3:133-42.

14 Wimberley NW, Bass JB, Boyd BW, Kirkpatrick MB, Serio RA, Pollock HM. Use of a bronchoscopic protected catheter brush for the diagnosis of pulmonary infections. Chest 1982;81:556-62.

15 Gaussorgues P, Piperno D, Bachmann P, Boyer F, Jean G, Gerard M, et al. Comparison of nonbronchoscopic bronchoalveolar lavage to open lung biopsy for the bacteriologic diagnosis of pulmonary infections in mechanically ventilated patients. Intensive Care Med 1989;15:94-8.

16 Pham LH, Brun-Buisson C, Legrand P, Rauss A, Verra F, Brochard L, et al. Diagnosis of nosocomial pneumonia in mechanically ventilated patients: comparison of a plugged telescoping catheter with the protected specimen brush. Am Rev Respir Dis 1991;143:1055-61.

17 Marquette CH, Georges H, Wallet F, Ramon P, Saulnier F, Nevière R, et al. Diagnostic efficiency of endotracheal aspirates with quantitative bacterial cultures in intubated patients with suspected pneumonia. Comparison with the protected specimen brush. Am Rev Respir Dis 1993;148:138-44.

18 El Ebiary M, Torres A, Gonzales J, Puig dela Bellacasa J, Garcia C, Jimenez de Anta MT, et al. Quantitative cultures of endotracheal aspirates for the diagnosis of ventilator-associated pneumonia. Am Rev Respir Dis 1993; 148:1552-7.

19 Montravers P, Fagon JY, Chastre J, Lecso M, Dombret MC, Trouillet $\mathrm{JL}$, et al. Follow-up protected specimen brushes to assess treatment in nosocomial pneumonia. Am Rev Respir Dis 1993;147:38-44.

20 Rouby JJ, Martin de Lassale E, Poete P, Nicolas MH, Bodin L, Jarlier V, et al. Nosocomial bronchopneumonia in the critically ill: histologic and bacteriologic aspects. Am Rev Respir Dis 1992;146:1059-66.

21 Chastre J, Viau F, Brun P, Pierre J, Dauge MC, Bouchama A, et al. Prospective evaluation of the protected specimen brush for the diagnosis of pulmonary infections in ventilated patients. Am Rev Respir Dis 1984; 130:924-9.

22 Torres A, El-Ebiary M, Padro L, Gonzales J, Puig de la Bellacasa J, Ramirez $\mathrm{J}$, et al. Validation of different techniques for the diagnosis of ventilator, et al. Validation of different techniques for the diagnosis of ventilator-

associated pneumonia. Am f Respir Crit Care Med 1994;149:324-31.
23 Wilson WR, Dolan T, Washington JA, Brown AL, Ritts RE. Clinical significance of postmortem cultures. Arch Pathol 1972;94:244-9.

24 Higuchi JH, Coalson JJ, Johanson WG. Bacteriologic diagnosis of nosocomial pneumenia in primates. Usefulness of the protected specimen brush. Am Rev Respir Dis 1982;125:53-7.

25 Johanson WG, Seidenfeld JJ, Gomez P, De Los Santos R, Coalson JJ. Bacteriologic diagnosis of nosocomial pneumonia following prolonged mechanical ventilation. Am Rev Respir Dis 1988;137:259-64.

26 Rouby JJ, Rossignon MD, Nicolas MH, Martin de Lassale E, Cristin S, Grosset J, et al. A prospective study of protected bronchoalveolar lavage in the diagnosis of nosocomial pneumonia. Anesthesiology 1989;71:679-85.

27 Torres A, Martos A, Puig de la Bellacasa J, Ferrer M, El-Ebiary M, Gonzales $\mathrm{J}$, et al. Specificity of endotracheal aspiration, protected specimen brush, and bronchoalveolar lavage in mechanically ventilated patients. Am Rev Respir Dis 1993;147:952-7. 